\title{
Incidence and risk factors of severe adverse events with nevirapine-based antiretroviral therapy in HIV-infected women. MTCT-Plus program, Abidjan, Côte d'Ivoire
}

\author{
Patrick A Coffie1,2,3, Besigin Tonwe-Gold1,2,3, Aristophane K Tanon+4, Clarisse Amani-Bosse1, Gédéon Bédikou1, \\ Elaine J Abrams5, François Dabis²,3 and Didier K Ekouevi*1,2,3
}

\begin{abstract}
Background: In resource-limited settings where nevirapine-containing regimen is the preferred regimen in women, data on severe adverse events (SAES) according to CD4 cell count are limited. We estimated the incidence of SAEs according to CD4 cell count and identify their risk factors in nevirapine-treated women.

Methods: All HIV-infected women who initiated nevirapine-containing regimen in the MTCT-Plus operational program in Abidjan, Côte d'Ivoire, were eligible for this study. Laboratory and clinical (rash) SAEs were classified as grade 3 and 4. Cox models were used to identify factors associated with the occurrence of SAEs.

Results: From August 2003 to October 2006, 290 women initiated a nevirapine-containing regimen at a median CD4 cell count of 186 cells $/ \mathrm{mm}^{3}$ (IQR 124-266). During a median follow-up on treatment of 25 months, the incidence of all SAEs was 19.5/100 patient-years. The 24-month probability of occurrence of hepatotoxicity or rash was not different between women with a CD4 cell count $>250$ cells $/ \mathrm{mm}^{3}$ and women with a CD4 cell count $\leq 250$ cells $/ \mathrm{mm}^{3}(8.3 \%$ vs. 9.9\%, Log-rank test: $p=0.75$ ). In a multivariate proportional hazard model, neither CD4 cell count $>250$ cells $/ \mathrm{mm}^{3}$ at treatment initiation nor initiation NVP-based regimen initiated during pregnancy were associated with the occurrence of SAES.

Conclusion: CD4 cell count $>250$ cells $/ \mathrm{mm}^{3}$ was not associated with a higher risk of severe hepatotoxicity and/or rash, as well as initiation of ART during pregnancy. Pharmacovogilance data as well as meta-analysis on women receiving NVP in these settings are needed for better information about NVP toxicity.
\end{abstract}

\section{Background}

At the end of 2007, more than three million people were receiving Highly Active Antiretroviral Therapy (HAART) in resource-limited settings [1]. The first-line regimen recommended by the World Health Organization (WHO) in resource-limited includes two nucleoside reverse transcriptase inhibitors (NRTI) with one nonnucleoside reverse transcriptase inhibitor (NNRTI) [2].

Nevirapine (NVP) is the preferred NNRTI in first-line antiretroviral regimens in pregnancy because of substantial clinical experience with pregnant women and its

\footnotetext{
* Correspondence: didier.ekouevi@gmail.com

1 Programme MTCT-Plus, ACONDA, BP: 1954 Abidjan 18, Abidjan, Côte d'Ivoire Full list of author information is available at the end of the article
}

proven efficacy in reducing mother-to-child transmission $[3,4]$. The most frequent adverse events of NVP are hepatotoxicity and cutaneous rash. Studies from developed countries report an increased risk of severe hepatotoxicity and cutaneous rash in women with CD4 count $>250$ cells $/ \mathrm{mm}^{3}$ [5-9]. Based on these findings, WHO recommends avoiding NVP in women, including pregnant women, with CD4 counts between 250 and 350 cells/ $\mathrm{mm}^{3}$, or if no other options exist as it is often the case in resource-limited settings, using it with caution and close monitoring during the first 12 weeks of therapy $[2,8]$. Although some cases have been reported in pregnant women, it is still not known whether pregnancy increases the risk of the occurrence of hepatotoxicity or rash [9-11]. 
In resource-limited settings, where NVP is widely used in women and during pregnancy whatever the level of CD4, there is little data on the occurence of hepatotoxicity and/ or rash according to CD4, and all except one study did not find this association [12-16].

We hypothesize that HAART initiation among pregnant HIV-infected women or HIV-infected women with CD4 count $>250$ cells $/ \mathrm{mm}^{3}$ may be associated with an increased frequency of SAEs. Thus, we estimated in the MTCT-Plus program in Abidjan, Côte d'Ivoire, the incidence rate of all severe adverse events (SAEs) according to CD4 cell count and pregnancy status, especially hepatotoxicity and/or rash and investigated their risk factors in women initiating NVP-based HAART.

\section{Methods}

\section{Study design and setting}

A prospective cohort study was conducted in Abidjan, Côte d'Ivoire between August 2003 and October 2006 among women enrolled in the MTCT-Plus program, which is built upon existing prevention of mother-tochild transmission (PMTCT) services and provides HIVinfected women, their partners, and their children, holistic family care with unrestricted access to HAART for eligible patients $[17,18]$.

\section{Study population}

All HIV-infected women were included in this study if they initiated NVP-based HAART according to the following eligibility criteria: WHO clinical stage 2 (until December 2004) or stage 3 and CD4+ T lymphocytes (CD4 cell count) $<350$ cells $/ \mathrm{mm}^{3}$, or stage 4 regardless of CD4 cell count, or CD4 cell count $<200$ cells $/ \mathrm{mm}^{3}$. The women had to meet one additional biological criterion before initiating HAART: aminotransferase and/or alaninetransferase levels no more than three times the upper limit of the normal range. All women with a CD4 cell count $<350$ cells $/ \mathrm{mm}^{3}$ were also prescribed co-trimoxazole prophylaxis. All women were ARV-naive with the exception of prior PMTCT exposure.

\section{Ethical aspects}

The MTCT-Plus program was reviewed by the institutional review board (IRB) from Columbia University in 2000 (principal sponsor) and was not considered a research project but rather a demonstration program in the context of the ARV roll-out. As an operational HIV care and treatment program MTCT-Plus program was exempted from review by the IRB from the Ministry of health of Côte d'Ivoire.

\section{Enrollment and follow-up}

Maternal socio-demographic, clinical and biological characteristics were recorded at enrollment in the pro- gram and at initiation of HAART [18]. During weekly follow-up visits for the first two months and monthly visits thereafter, clinical signs and symptoms, drug intake, and tolerance were assessed. Between scheduled visits, women had free access to the study clinics for medical problems. Total blood cell count (MaxM, BeckmanCoulter, Miami, FL, USA), serum liver enzymes, and serum creatinine were monitored according to the following schedules: in women starting HAART after delivery at baseline, month 1 , and every three months thereafter; in women starting HAART prepartum at baseline, week 2 , month 1 , and monthly thereafter during pregnancy. CD4 cell count were measured using a dualplatform flow cytometry technique with an automated blood cell counter (MaxM, BeckmanCoulter, Miami, FL, USA), at the screening visit and then every six months. Serology for hepatitis B was not routinely performed. All blood samples were processed in the same laboratory.

\section{Outcomes and definitions}

The outcomes of interest were the occurrence of SAEs defined as clinical and biological grade $3 / 4$ adverse events according to the Agence Nationale de la Recherche sur le Sida et les hepatites virales (ANRS) table for grading the severity of adult adverse events [19]: at least one haemoglobinaemia measurement $<70 \mathrm{~g} / \mathrm{l}$, one neutrophil count $<750 / \mathrm{mm}^{3}$, one amino and/or alaninetransferase measurement more than five times the upper limit of the normal range and any extended papulovesicular or oozing eruption, palpable purpura (suggestive of vasculitis), polymorphous erythaema, small-size cutaneous or mucous ulcerations, any blistering cutaneous and/or mucosal lesions (Lyell or Stevens-Johnson), febrile erythrodermia, whether or not associated with other signs indicative of hypersensitivity, cutaneous necrosis requiring surgical excision. All SAEs were reported by clinicians during follow-up visits and subsequently validated by two expert clinicians. If the experts disagree, a third expert was called upon to avoid misclassification and to validate a final diagnosis.

\section{Statistical analysis}

Group comparisons used Student's t-test, non-parametric Mann-Whitney $U$ test or variance analysis for continuous variables, and the $\mathrm{Chi}^{2}$ test or Fisher's exact test for categorical variables. The incidence rate of SAEs per 100 patient-months or years was estimated with its $95 \%$ confidence interval (CI). The Log-Rank test was used to compare the incidence rate between two groups. Univariable and then multivariable Cox regression analyses were performed to identify factors associated with the occurrence of these SAEs. All factors associated with the outcomes at a $P$ value $<0.25$ were included in the multivariable analysis. The CD4 cell count and WHO clinical stage at 
HAART initiation were kept in the final model. Adjusted hazard ratios (aHR) and their 95\% CI are reported with two-sided p-values. All analyses were performed in intent-to-treat and on treatment [20] with SAS software version 9.1 (SAS Institute, Cary, NC, USA).

\section{Results}

\section{Patients and follow-up}

From August 2003 to October 2006, 530 women were enrolled in MTCT-Plus and 290 (54.7\%) women initiated a NVP-containing regimen and were included in this study. Their median age at HAART initiation was 29 years (inter-quartile range [IQR] 26-33) and median CD4 cell count was 186 cells $/ \mathrm{mm}^{3}$ (IQR 124-266). Two-hundred and two women (70\%) initiated HAART with a CD4 cell count $\leq 250$ cells $/ \mathrm{mm}^{3}, 130(44.8 \%)$ were at WHO clinical stage 3 or 4, 125 (43.0\%) initiated HAART during pregnancy, and 287 (99.0\%) started co-trimoxazole. During a median follow-up on HAART of 25 months (IQR 14-30), seven women (2.4\%) were lost to follow-up, seven (2.4\%) stopped HAART on their own initiative and 16 (5.5\%) died. The baseline and follow-up characteristics of these women are summarized in Table 1.

\section{Antiretroviral therapy}

The first-line HAART regimen was ZDV/3TC/NVP in 265 women (91.4\%) and stavudine (d4T)/3TC/NVP in 25 women $(8.6 \%)$. In this cohort, 153 women $(52.8 \%)$ were previously exposed to a PMTCT regimen during a previous pregnancy: short-course (sc) ZDV and lamivudine plus single dose nevirapine (sdNVP) $(\mathrm{n}=84)$, scZDV plus $\operatorname{sdNVP}(\mathrm{n}=65)$ and scZDV alone $(\mathrm{n}=2)$. The median interval between exposure to PMTCT and initiation of HAART was 22 months (IQR 13-21).

\section{Incidence rate of severe adverse events}

A total of 104 SAEs were reported in 88 women $(30.3 \%)$ as follows: neutropenia $(n=60 ; 20.7 \%)$, anaemia $(n=17$; $5.9 \%)$, rash $(\mathrm{n}=15 ; 5.2 \%)$, hepatotoxicity $(\mathrm{n}=10 ; 3.4 \%)$, headache and neuropathy $(\mathrm{n}=1 ; 0.3 \%)$.

The overall incidence rate of SAEs was 19.5/100 patient-years (PY), (95\% CI 15.9-23.4): 13.3/100 PY (95\% CI 10.3-16.8) for neutropenia, 3.8/100 PY (95\% CI 2.26.0) for anemia, 3.3/100 PY (95\% CI 1.9-5.4) for rash, and 2.2/100 PY (95\% CI 1.1-4.0) for hepatotoxicity. The median delay between HAART initiation and occurrence of all SAEs was 3.0 months (IQR 1-6). It was 6.0 months (IQR 2.5-7.5) for neutropenia, 4.0 months (IQR 2-5) for anemia, 2.5 months (IQR 1-11) for hepatotoxicity, and 1.0 month (IQR 1-3) for rash. The overall probability of occurrence of SAEs was $17.0 \%$ (95\% CI 13.1-21.9\%) at month-3, 29.7\% (95\% CI 24.6-35.6\%) at month-12, 33.9\% (95\% CI 28.4-40.2\%) at month-24 (Figure 1).
Table 1: Baseline and follow-up characteristics of HIVinfected women in the MTCT-Plus program $(N=290)$.

\begin{tabular}{|c|c|}
\hline \multicolumn{2}{|l|}{ At initiation of treatment } \\
\hline \multicolumn{2}{|l|}{ Period at HAART initiation } \\
\hline $\begin{array}{l}\text { Pregnant/non pregnant, } \\
\mathrm{n}(\%)\end{array}$ & $125 / 165(43 / 57)$ \\
\hline \multicolumn{2}{|l|}{ Exposed women to PMTCT } \\
\hline $\begin{array}{l}\text { Exposed/no exposed, } \mathrm{n} \\
\text { (\%) }\end{array}$ & $153 / 137(53 / 47)$ \\
\hline Age, years, median [IQR] & 29 [26-33] \\
\hline$>29$ years & $137(47)$ \\
\hline Body mass index, $\mathrm{Kg} / \mathrm{m}^{2}[\mathrm{IQR}]$ & $22.3[20.1-25.3]$ \\
\hline$>18.5 *$ & $250(86)$ \\
\hline \multicolumn{2}{|l|}{ WHO clinical stage, n (\%) } \\
\hline 1 & $33(11)$ \\
\hline 2 & $127(44)$ \\
\hline 3 & $117(40)$ \\
\hline 4 & $13(5)$ \\
\hline CD4 counts, cells/mm $\mathrm{mm}^{3}[\mathrm{IQR}]$ & $186[124-266]$ \\
\hline$>250$ & $88(30)$ \\
\hline Co-trimoxazole, n (\%) & $287(99)$ \\
\hline $\begin{array}{l}\text { Haemoglobin level, g/l, } \\
\text { median [IQR] }\end{array}$ & $9.8[9-11]$ \\
\hline$\leq 9.8$ & $150(52)$ \\
\hline $\begin{array}{l}\text { Neutrophil count, } \mathrm{mm}^{3} \text {, } \\
\text { median [IQR] }\end{array}$ & 26392639 [1911-3712] \\
\hline$<1500$ & $28(10)$ \\
\hline \multicolumn{2}{|l|}{ HAART regimen, $n$ (\%) } \\
\hline ZDV/3TC/NVP & $265(91)$ \\
\hline $\mathrm{d} 4 \mathrm{~T} / 3 \mathrm{TC} / \mathrm{NVP}$ & $25(9)$ \\
\hline $\begin{array}{l}\text { Alanine aminotransferase, } \mathrm{UI} \text {, } \\
\text { median [IQR] }\end{array}$ & $15[11-24]$ \\
\hline$<31 \mathrm{IU} / \mathrm{L}^{*}$ & $240(83)$ \\
\hline $\begin{array}{l}\text { Aspartate aminotransférase, } \\
\text { Ul, median [IQR] }\end{array}$ & 24 [19-31] \\
\hline$<32 \mathrm{IU} / \mathrm{L}^{*}$ & $235(81)$ \\
\hline
\end{tabular}

Follow-up

Cumulative, person-months

6388

Per patient, months, median

$25[14-30]$

[IQR]

Status on study termination

$\begin{array}{lc}\text { Dead, } \mathrm{n}(\%) & 16(6) \\ \text { Lost to follow-up, } \mathrm{n}(\%) & 7(2) \\ \text { Alive, } \mathrm{n}(\%) & 267(92)\end{array}$

HAART: Highly active antiretroviral therapy; PMTCT: prevention to mother-to-child transmission; WHO: World Health Organization; IQR: interquartile range; ZDV: zidovudine; 3TC: lamivudine; NVP: nevirapine; d4T: stavudine; ALT: alanine aminotransferase; AST: aspartate aminotransferase; IU:

International unity;

* upper limit of normal 
Among the 16 women who died, eight (50.0\%) had a history of SAEs. Table 2 describes the death cases. When considering death or SAEs, the 12-month and 24-month were $32.1 \%$ (95\% CI 26.8-38.0\%) and 36.6\% (95\% CI 30.9$42.9 \%$ ) respectively (Figure 1 ).

\section{Severe adverse events and CD4 count at the initiation of treatment}

The median CD4 cell count was 151 cells $/ \mathrm{mm}^{3}$ (IQR 106190) for women who initiated HAART with a CD4 cell count $\leq 250$ cells $/ \mathrm{mm}^{3}$ and 303 cells $/ \mathrm{mm}^{3}$ (IQR 275-331) for those who initiated HAART at $>250$ cells $/ \mathrm{mm}^{3}$. Baseline characteristics such as age, body mass index (BMI), and WHO clinical stage were comparable between the two groups except for the proportion of women who initiated HAART during pregnancy: in women with a CD4 cell count $\leq 250$ cells $/ \mathrm{mm}^{3}, 47 \%$ initiated HAART while pregnant $v s .34 \%$ in women with a CD4 cell count $>250$ cells $/ \mathrm{mm}^{3}(\mathrm{p}=0.04)$. The 24 -month probability of occurrence of rash or hepatotoxicity was not different between women with a CD4 cell count $>250$ cells $/ \mathrm{mm}^{3}$ and women with a CD4 cell count $\leq 250$ cells $/ \mathrm{mm}^{3}(8.3 \%$ vs. 9.9\%, Log-rank test: $\mathrm{p}=0.75)$. Similarly, this 24-month probability was not different between the two groups when considering death and SAEs combined (27.0\% vs. $40.7 \%$ respectively, Log-rank test, $\mathrm{p}=0.08$ ).

\section{Severe adverse events and period of HAART initiation}

The baseline characteristics such as age, BMI, WHO clinical stage and CD4 cell count, were comparable between the women who initiated HAART during pregnancy (group 1) and those who did not (group 2). The median interval between HAART initiation and delivery was 3.0 months (IQR 2-3) in women in group 1 and during this period, the incidence rate was $3.4 / 100$ patient-months (IQR 1.7-6.1) for all SAEs and 1.6/100 patient-months (IQR 0.5-3.6) for rash and/or hepatotoxicity. In women in group 2, when restricting the analyses to the first three months of follow-up after HAART initiation, the incidence rate was 6.1/100 patient-months [IQR 4.1-8.6] for all SAE and 2.5/100 patient-months [IQR 1.3-4.3] for rash and/or hepatotoxicity. The 3-month probability of occurrence of rash or hepatotoxicity did not differ between groups 1 and 2 (5.3\% vs. 7.5\%; Log-Rank test, p = 0.35) (Figure 2).

\section{Evolution of severe adverse events}

One hundred and four SAEs were reported and led to a change in treatment in 47 cases. NVP was switched to a protease inhibitor secondary to grade 3 rash $(n=15)$ or grade $3 / 4$ liver toxicity $(n=4)$, or to $\operatorname{EFV~}(n=3)$ or abacavir $(n=1)$ owing to grade $3 / 4$ liver toxicity. For two cases of hepatotoxicity, NVP was kept in the HAART regimen because of a transient elevation of liver function enzymes. Zidovudine was switched to stavudine owing to grade $3 / 4$ anaemia $(n=15)$, neutropenia $(n=7)$, and headache $(n=1)$. The SAEs resolved after interruption of co-trimoxazole for two cases of anaemia and 53 cases of neutropenia. Stavudine was switched to abacavir for one case of neuropathy.

Severe adverse events were reported in eight of 16 women who died (Table 2). One death attributed to severe anaemia may have been drug-related or exacerbated but further details around the cause of death were not available. For one woman, the causes of death were unknown. Zidovudine was switched to stavudine 9 months after HAART initiation because of a persistent severe neutropenia. About 16 months initiating stavudine, she presented myalgia and received an analgesic. An appointment was given to her 10 days later but she did not come. She died at home one month later.

\section{Factors associated with the of severe adverse events}

In a multivariate Cox regression analysis, none of the factors investigated (age, previous exposure to PMTCT regimen, BMI, hemoglobin and neutrophil at baseline, and HAART initiation during pregnancy) was statistically associated with the first occurrence incidence of SAEs ( $\mathrm{n}$ $=88$ ) after adjusting for CD4 cell count and WHO clinical stage at enrollment (Table 3 ). When restricting the analyses to severe hepatotoxicity, only ALT $\geq 31 \mathrm{UI} / \mathrm{L}$ was associated with these SAEs (Table 3 ). The result did not change when using combined outcomes: rash or severe hepatotoxicity (data not shown). Similarly, when restricting the analyses to anaemia and/or neutropenia, only low baseline neutrophil count $<1500 / \mathrm{mm}^{3}$ was associated with these SAEs (Table 3). Analysis with on treatment approach led to similar results (data not shown).

\section{Discussion}

In Abidjan, Côte d'Ivoire, we followed 290 HIV-infected women who started ZDV/3TC/NVP in combination with co-trimoxazole. During a median follow-up on HAART of 25 months, we observed a relatively high incidence rate of SAEs of 19.5/100 patient-years. The risk factors identified for developing a SAE were elevated baseline transaminase levels for the occurrence of a rash and/or hepatotoxicity and low baseline neutrophil count for anaemia and/or neutropenia.

This high incidence rate of SAEs observed in our study was due to the high incidence of grade $3 / 4$ neutropenia (13.3/100 PY), probably due to the association ZDV and co-trimoxazole. Approximately $90 \%(53 / 60)$ of grade $3 / 4$ neutropenia disappeared after the interruption of co-trimoxazole and only seven women had to stop ZDV owing to neutropenia. This result is consistent with a study conducted in Côte d'Ivoire where the 118 patients with incident grade $3 / 4$ neutropenia were all receiving co- 


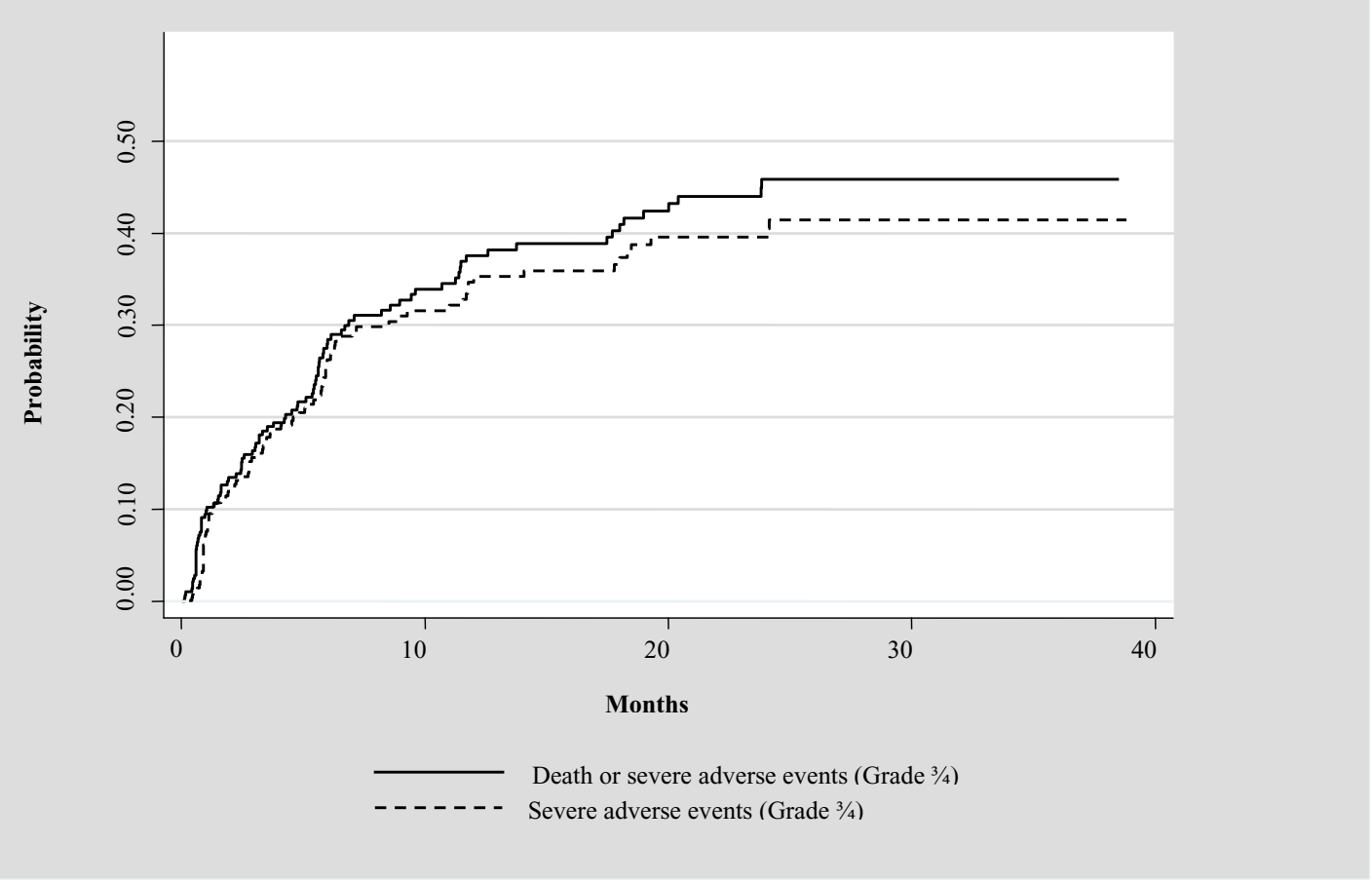

\begin{tabular}{lcccc}
\hline Time of occurrence of first SAEs & Month-3 & Month-6 & Month-12 & Month-24 \\
\hline Probability of SAEs occurrence $(95 \%$ CI) & $16.9(13.1-21.9)$ & $24.2(19.5-29.7)$ & $29.7(24.6-35.6)$ & $33.9(28.4-40.2)$ \\
No. of patients at risk & 228 & 209 & 161 & 108 \\
\hline
\end{tabular}

\begin{tabular}{lcccc}
\hline Time of occurrence of death or SAEs & Month-3 & Month-6 & Month-12 & Month-24 \\
\hline Probability of SAEs occurrence $(95 \% \mathrm{CI})$ & $17.3(13.4-22.2)$ & $24.4(19.8-29.9)$ & $31.3(26.1-37.8)$ & $37.8(31.1-43.2)$ \\
No. of patients at risk & 226 & 197 & 160 & 99 \\
\hline
\end{tabular}

SAEs: severe adverse events

CI: confidence interval

Figure 1 Probability of occurrence of severe adverse events (grade $3 / 4$ ) and/or death in women initiating a nevirapine-based antiretroviral therapy in the MTCT-Plus program in Abidjan, Côte d'Ivoire

trimoxazole when the neutropenia was detected. After the interruption of co-trimaxazole, $73 \%$ of these SAEs disappeared [21]. The incidence rate of anaemia estimated in our study is also consistent with this study conducted in Côte d'Ivoire and other studies in Africa [2123].

Concerning cutaneous rash or hepatotoxicity, most reports have expressed the risk of SAEs using a cruder indicator, the cumulative frequency. We estimated that the cumulative frequencies of grade $3 / 4$ cutaneous rash and hepatotoxicity were $5.2 \%$ et $3.4 \%$, respectively. This result is consistent with other studies realized in resource-limited settings which have found frequencies of grade $3 / 4$ rash ranging between $2.4 \%$ and $4.6 \%$ [13-
$16,24 \mathrm{]}$ and grade $3 / 4$ hepatotoxicity ranging between $1.5 \%$ and $6.6 \%$ [12-16]. The frequency of severe hepatotoxicity is lower in resource-limited settings than in developed countries where this frequency is between $5.8 \%$ and $17.6 \%[7,9,25-27]$. This difference could be explained by a different susceptibility to NVP between people from resource-limited settings and Caucasian origin [28], a different distribution of the frequency of some risk factors such as hepatitis B and C [27], drug use and alcohol consumption. However, in the studies from resource-limited settings, the frequency of these risk factors has not been estimated. The other risks factors associated with the hepatotoxicity and/or rash reported in litterature, such as baseline HIV-1 RNA level, NVP plasma concentration, 
Table 2: Causes of death among HIV-infected women followed in the MTCT-Plus program and treated with NVP-based HAART.

\begin{tabular}{|c|c|c|c|c|c|c|c|c|}
\hline$\#$ & $\begin{array}{l}\text { CD4 count* } \\
\text { cells } / \mathrm{mm}^{3}\end{array}$ & $\begin{array}{c}\text { Pregnancy at } \\
\text { HAART initiation }\end{array}$ & Regimen* & Cause of death & $\begin{array}{l}\text { Time of death** } \\
\text { (months) }\end{array}$ & History of SAEs & Description of SAEs & $\begin{array}{c}\text { Time of } \\
\text { occurrence of } \\
\text { SAEs** (months) }\end{array}$ \\
\hline 1 & 253 & No & AZT/3TC/NVP & Mulitple myeloma & 26.7 & Yes & Neutropenia grade 3 & 7.2 \\
\hline 2 & 241 & No & AZT/3TC/NVP & Hepatitis B & 24.6 & Yes & Hepatotoxicity grade 3 & 24.2 \\
\hline 3 & 332 & No & AZT/3TC/NVP & Hepatitis B & 13.3 & Yes & Anaemia grade 4 & 1.2 \\
\hline 4 & 230 & No & AZT/3TC/NVP & Unknown & 24.9 & Yes & Neutropenia grade 4 & 9.2 \\
\hline 5 & 271 & Yes & AZT/3TC/NVP & Severe anaemia & 3.7 & Yes & Anaemia grade 4 & 3.4 \\
\hline 6 & 250 & No & AZT/3TC/NVP & AIDS terminal & 14.0 & Yes & Neutropenia Grade3 & 4.6 \\
\hline 7 & 193 & No & AZT/3TC/NVP & Cerebral malaria & 20.8 & Yes & Rash grade 3 & 0.7 \\
\hline 8 & 39 & Yes & AZT/3TC/NVP & AIDS terminal & 10.6 & Yes & Rash grade 3 & 2.0 \\
\hline 9 & 170 & Yes & AZT/3TC/NVP & AIDS terminal & 20.4 & No & & \\
\hline 10 & 186 & Yes & $\mathrm{d} 4 \mathrm{~T} / 3 \mathrm{TC} / \mathrm{NVP}$ & Eclampsia & 1.8 & No & & \\
\hline 11 & 7 & No & AZT/3TC/NVP & Pneumonia & 6.9 & No & & \\
\hline 12 & 226 & No & $\mathrm{d} 4 \mathrm{~T} / 3 \mathrm{TC} / \mathrm{NVP}$ & Renal tumor & 2.0 & No & & \\
\hline 13 & 121 & No & AZT/3TC/NVP & Cerebral malaria & 10.0 & No & & \\
\hline 14 & 84 & Yes & AZT/3TC/NVP & Fever & 9.8 & No & & \\
\hline 15 & 24 & No & AZT/3TC/NVP & Meningitis & 7.4 & No & & \\
\hline 16 & 288 & Yes & AZT/3TC/NVP & Gastric perforation & 12.9 & No & & \\
\hline
\end{tabular}

* At initiation of treatment, SAEs = Severe adverse events grade III/IV

** After HAART initiation 


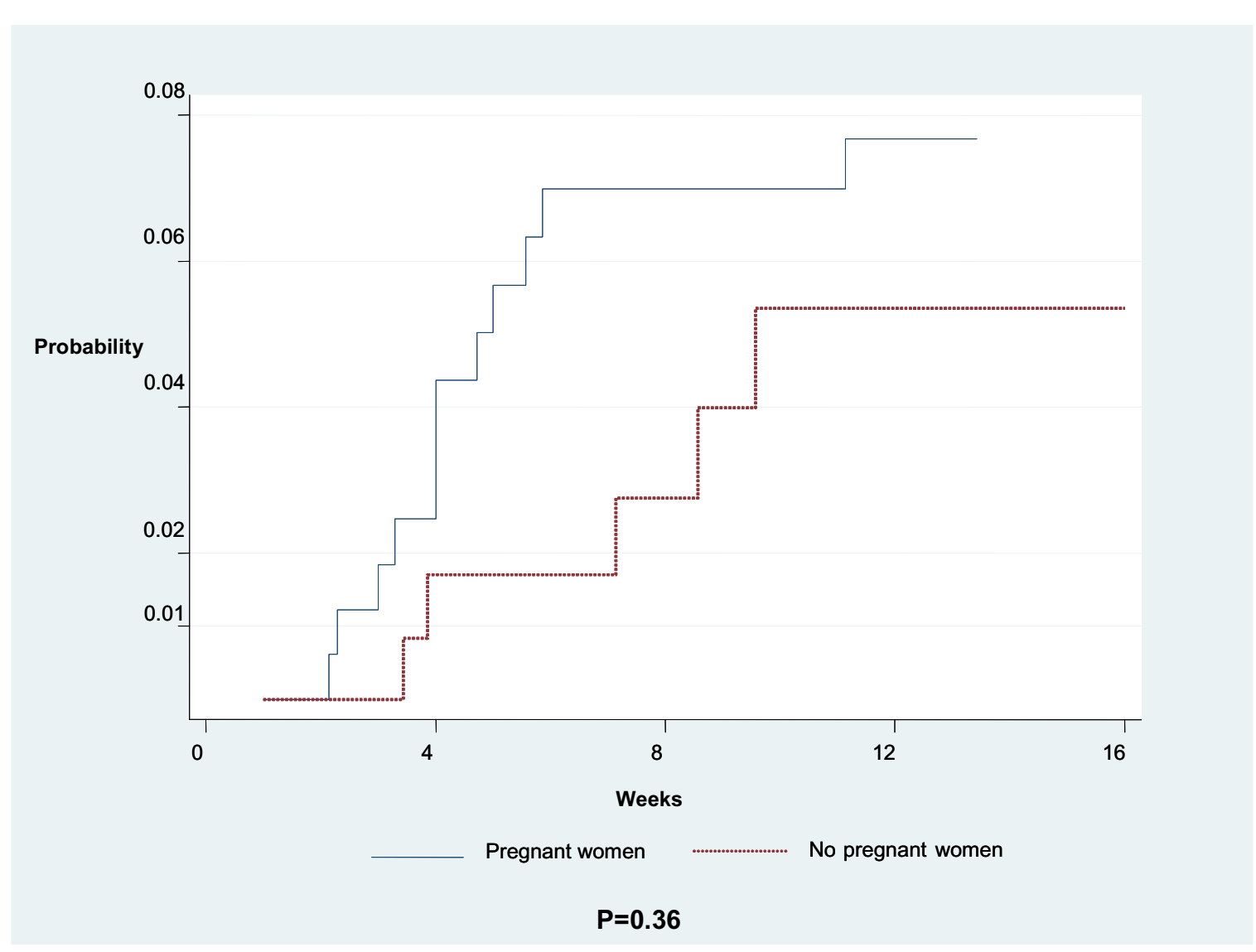

\begin{tabular}{lcccc}
\hline & \multicolumn{2}{c}{ HAART in non pregnant women } & \multicolumn{2}{c}{ HAART in pregnant women } \\
\hline Time of occurrence of SAEs & Day 30 & Day 90 & Day 30 & Day 90 \\
\cline { 2 - 5 } Probability of occurrence of SAEs & $4.9(2.5-9.6)$ & $7.5(4.3-12.7)$ & $2.5(0.8-7.5)$ & $5.3(2.1-12.2)$ \\
No. of patients at risk & 154 & 144 & 118 & 60 \\
\hline
\end{tabular}

SAEs: severe adverse events

CI: confidence interval

HAART: Highly active antiretroviral therapy

Figure 2 Probability of occurrence of grade III/IV rash or hepatotoxicity during the three months of follow-up in women initiating a nevirapine-based antiretroviral therapy according to the period of the initiation of treatment (pregnant and non pregnant women) . MTCT-Plus program in Abidjan, Côte d'Ivoire

and genetic factors, could not be investigated in our study because there are not recorded in routine circumstances in Côte d'Ivoire.

In our cohort, a CD4 count $>250$ cells $/ \mathrm{mm}^{3}$ was not associated with occurrence of SAEs, including severe hepatotoxicity and/or cutaneous rash, as was the case in most studies conducted in resource-limited-settings [1316]. One study conducted in Mozambique among 146 pregnant women found a higher rate of severe hepatotoxicity in women with CD4 $>250$ cells $/ \mathrm{mm}^{3}(6.0 \%$ vs $0.0 \%$; $\mathrm{p}$ $=0.02)[12]$. Generally in resource-limited-settings, a great majority of HIV-infected patients initiate their treatment late, generally when the CD4 cell count is below 200 cells $/ \mathrm{mm}^{3}[29,30]$. In our study, the median CD4 cell count was 188 cells $/ \mathrm{mm}^{3}$ and only a few women (30\%) had a CD4 cell count above 250 cells $/ \mathrm{mm}^{3}$. Moreover in this cohort, $47 \%$ of the women who had a CD4 cell count $\leq 250$ cells $/ \mathrm{mm}^{3}$ initiated HAART during pregnancy, which may have resulted in an underestimation of the CD4 count values due to physiological hemodilution [31]. We also found that the initiation of HAART during pregnancy was not associated with the occurrence of 
Table 3: Factors associated with severe adverse events in women initiating NVP-based antiretroviral therapy.

\begin{tabular}{|c|c|c|c|c|c|c|c|c|c|}
\hline & \multicolumn{3}{|c|}{ All severe adverse events $(\mathrm{N}=\mathbf{8 8}) \dagger$} & \multicolumn{3}{|c|}{ Severe hepatotoxicity $(\mathrm{N}=10)$} & \multicolumn{3}{|c|}{ ZDV-related severe averse events $(\mathrm{N}=71)$} \\
\hline & HR & $95 \% \mathrm{Cl}$ & $\mathbf{p}$ & HR & $95 \% \mathrm{Cl}$ & $\mathbf{p}$ & HR & $95 \% \mathrm{Cl}$ & $\mathbf{p}$ \\
\hline \multicolumn{10}{|l|}{ Age (years) } \\
\hline$\geq 30(n=137)$ & 1.03 & $0.67-1.59$ & 0.90 & 1.37 & $0.37-5.06$ & 0.64 & 0.92 & $0.57-1.49$ & 0.74 \\
\hline$<30(n=153)$ & 1.00 & - & - & 1.00 & - & - & 1.00 & - & - \\
\hline \multicolumn{10}{|l|}{ Body mass index $\left(\mathrm{Kg} / \mathrm{m}^{2}\right)$} \\
\hline$<18(n=40)$ & 1.08 & $0.53-2.20$ & 0.05 & & & & 1.12 & $0.52-2.42$ & 0.78 \\
\hline$\geq 18(n=160)$ & 1.00 & - & - & & & & 1.00 & - & - \\
\hline \multicolumn{10}{|l|}{$\mathrm{CD} 4+$ count $/ \mathrm{mm}^{3}$} \\
\hline$>250(n=88)$ & 0.68 & $0.41-1.12$ & 0.14 & 1.75 & $0.48-6.39$ & 0.40 & 0.64 & $0.36-1.14$ & 0.13 \\
\hline$\leq 250(n=202)$ & 1.00 & - & - & 1.00 & - & - & 1.00 & - & - \\
\hline \multicolumn{10}{|l|}{ WHO staging } \\
\hline Stage 3 or $4(n=130)$ & 1.00 & $0.63-1.58$ & 0.99 & 1.31 & $0.36-4.74$ & 0.68 & 1.07 & $0.65-1.79$ & 0.77 \\
\hline Stage 1 or $2(n=160)$ & 1.00 & - & - & 1.00 & - & - & 1.00 & - & - \\
\hline \multicolumn{10}{|l|}{ ALT (IU/L) } \\
\hline$\geq 31(n=50)$ & 1.58 & $0.89-2.78$ & 0.12 & 7.09 & $1.59-31.62$ & 0.01 & 1.10 & $0.57-2.15$ & 0.78 \\
\hline$<31(n=240)$ & 1.00 & - & - & 1.00 & - & - & 1.00 & - & - \\
\hline \multicolumn{10}{|l|}{ Neutrophil level $\left(/ \mathrm{mm}^{3}\right)$} \\
\hline$<1500(n=28)$ & 1.51 & $0.76-2.98$ & 0.24 & & & & 2.20 & $1.09-4.43$ & 0.03 \\
\hline$\geq 1500(n=262)$ & 1.00 & - & - & & & & 1.00 & - & - \\
\hline \multicolumn{10}{|l|}{ Hemoglobin level (g/dL) } \\
\hline$\leq 9.8(n=150)$ & 1.15 & $0.73-1.82$ & 0.56 & 0.66 & $0.16-2.79$ & 0.57 & 1.35 & $0.81-2.23$ & 0.25 \\
\hline$>9.8(n=140)$ & 1.00 & - & - & 1.00 & - & - & 1.00 & - & - \\
\hline \multicolumn{10}{|l|}{ Status of pregnancy } \\
\hline Pregnant $(n=125)$ & 0.98 & $0.60-1.64$ & 0.98 & 1.22 & $0.22-6.62$ & 0.82 & 1.11 & $0.65-1.91$ & 0.70 \\
\hline Non pregnant $(n=165)$ & 1.00 & - & - & 1.00 & - & - & 1.00 & - & - \\
\hline
\end{tabular}

Multivariable Cox regression analyses. MTCT-Plus program, Abidjan, Côte d'Ivoire (2003-2006).

HAART: Highly active antiretroviral therapy; WHO: World Health Organization; IQR: interquartile range; NVP: nevirapine; ALT: alanine aminotransferase; OR: odds ratio; aOR: adjusted odds ratio;

$\mathrm{Cl}$ : confidence interval, + If a woman had multiple severe adverse event 
severe rash or hepatotoxicity. We observed that the median duration of follow-up of pregnant women was relatively short (three months) but covered the higherrisk period for occurrence of rash or hepatotoxicity.

When investigating the causes of death, we found that half of these women (eight) had a history of SAEs during their follow up and two cases can be associated with medication toxicity: the woman who died after presenting grade 4 anaemia and those who died after presenting myalgia. This could be due to lactic acidosis. For the other deaths, it is difficult to attribute them to adverse events because of the delay between the history of SAEs and the time of death as well as the fact that documenting cause of death in these settings is a real challenge. Further pharmacovigilance studies should be conducted to document the cause of death in relation to SAEs.

This study had two main limitations. First, the study sample size was relatively small. This could reduce the power to detect difference between the risk factor groups and so the results should be interpreted with caution. However, our results provided additional information on the relation between CD4 counts $>250$ cells $/ \mathrm{mm}^{3}$, pregnancy and severe adverse events. Few previous studies in sub-Saharan Africa evaluated this association and did not find any difference [13-16]. Second, we did not include data on hepatitis B virus, hepatitis $C$, alcohol consumption and drug use which are not routinely collected in Cote d'Ivoire's national HIV program.

Overall, data reported in this MTCT-Plus cohort is reassuring about the safety of NVP-based HAART in routine circumstances. We did not observe severe events such as Stevens-Johnson syndrome or Lyell syndrome, and almost all the SAEs disappeared after discontinuation of the incriminated drug.

\section{Conclusion}

This prospective cohort study provides additional data in West Africa where CRF02 is the predominant of HIV-1 subtype and where the population was different. As shown by almost all studies conducted in resource-limited settings, including our study, a high absolute CD4 cell count was not associated with a higher risk of severe hepatotoxicity and/or rash, as well as pregnancy. However, as the sample size of these studies was limited, these results should be interpreted with caution. Data on women receiving NVP in resource-limited settings remain limited and there is a pressing need for better information about NVP toxicity in these settings. We believe that further studies especially meta-analyze with data available in low-income countries are urgently needed. NVP-based HAART should continue to be used with caution and close monitoring in eligible women for HAART with absolute CD4 cell count between 250 and
350 cells $/ \mathrm{mm}^{3}$ and in eligible pregnant women in resource-limited settings if no other options exist.

\section{Competing interests}

The authors declare that they have no competing interests.

\section{Authors' contributions}

PAC, BTG, AKT, CAB, GB, EJA, FD and DKE agree with the manuscript's results and conclusions. PAC and DKE designed the study, PAC, CAB, GB collected the data. PAC and DKE analyzed and interpreted the data: PAC, BTG, AKT, CAB, GB, EJA, FD and DKE contributed to the writing of the manuscript. There is no conflict interest to declare. All authors read and approved the final manuscript.

\section{Acknowledgements}

The authors thank the Secretariat of the MTCT-Plus Initiative at Columbia University, the ACONDA Cote d'Ivoire team, the CeDReS team, the Ditrame Plus study clinic team, as well as all the patients (originated from the ANRS 1201/ 1202 Ditrame Plus project) enrolled in this programme and their families. The primary sponsor of the Ditrame Plus project was the French Agence Nationale de Recherches sur le Sida et les hépatites virales (ANRS), France. The MTCT-Plus care and treatment programme in Abidjan is supported by the MTCT-Plus Initiative through the International Centre for AIDS care and treatment Programs (ICAP) at the Columbia University Mailman School of Public Health, New York, USA. The MTCT-Plus Initiative is funded by several private US foundations http://www.mtctplus.org.

Didier Koumavi Ekouevi was a fellow of the French Charity Sidaction (20022004) and a fellow of the European and Developing countries Clinical Trials Partnership (2005-2007). Patrick Ahuatchi Coffie is a fellow of the French Charity Sidaction (2009).

This study was presented in part at the 3rd International Aids Society Conference on HIV Pathogenesis and Treatment (abstract TuPe2.4C19), Rio de Janeiro, Brazil, 24-27 July 2005, and at the 4ème Conférence Francophone VIH/SIDA, Paris, France, 29-31 March 2007 (Poster \# 264).

\section{Author Details}

1Programme MTCT-Plus, ACONDA, BP: 1954 Abidjan 18, Abidjan, Côte d'Ivoire, 2Institut de Santé Publique, Epidémiologie et Développement (ISPED), Université Victor Segalen Bordeaux 2, 149 rue Leo Saignat, 33076, Bordeaux, France, ${ }^{3}$ Centre de Recherche INSERM U897, 149 rue Leo Saignat, 33076, Bordeaux, France, 4 Service des Maladies Infectieuses et Tropicales, Centre Hospitalier Universitaire Treichville, BP: 1954 Abidjan 18, Abidjan, Côte d'Ivoire and 5 MTCT-Plus Initiative, International Center for AIDS Care and Treatment Programs (ICAP), Mailman School of Public Health, Columbia University, 722 West 168th Street, 7th floor, New York, NY, 10032, USA New-York, NY, USA

Received: 28 September 2009 Accepted: 24 June 2010

Published: 24 June 2010

\section{References}

1. WHO/UNAIDS/UNICEF: Towards Universal Access. Scaling up priority HIV/AIDS interventions in the health sector. Progress Report 2008 [http:/ Lwww.who.int/hiv/pub/2008progressreport/en/J. Accessed date 02 March 2010

2. WHO: Antiretroviral therapy for HIV infection in adults and adolescents in resource-limited settings: Towards universal access. 2006 [http:// www.who.int/hiv/pub/guidelines/adult/en/l. Accessed date 02 March 2010

3. Jackson JB, Musoke P, Fleming T, Guay LA, Bagenda D, Allen M, Nakabiito C, Sherman J, Bakaki P, Owor M, Ducar C, Deseyve M, Mwatha A, Emel L, Duefield C, Mirochnick M, Fowler MG, Mofenson L, Miotti P, Gigliotti M, Bray D, Mmiro F: Intrapartum and neonatal single-dose nevirapine compared with zidovudine for prevention of mother-to-child transmission of HIV-1 in Kampala, Uganda: 18-month follow-up of the HIVNET 012 randomised trial. The Lancet 2003, 362(9387):859-868.

4. Moodley D, Moodley J, Coovadia H, Gray G, Mclntyre J, Hofmyer J, Nikodem C, Hall D, Gigliotti M, Robinson P, Boshoff L, Sullivan JL: South African Intrapartum Nevirapine Trial (SAINT) Investigators.I. A multicenter randomized controlled trial of nevirapine versus a combination of zidovudine and lamivudine to reduce intrapartum and 
early postpartum mother-to-child transmission of human immunodeficiency virus type 1 . J Infect Dis 2003, 187(5):725-735

5. Baylor MS, Johann-Liang R: Hepatotoxicity associated with nevirapine use. J Acquir Immune Defic Syndr 2004, 35(5):538-9.

6. Leith J, Piliero P, Storfer S, Mayers D, Hinzmann R: Appropriate use of nevirapine for long-term therapy. J Infect Dis 2005, 192(3):545-6. author reply 546

7. Stern JO, Robinson PA, Love J, Lanes S, Imperiale MS, Mayers DL: A comprehensive hepatic safety analysis of nevirapine in different populations of HIV infected patients. J Acquir Immune Defic Syndr 2003, 34(Suppl 1):S21-33

8. WHO: Antiretroviral Drugs for Treating Pregnant Women and Preventing HIV Infection in Infants. Guidelines on Care Treatment and Support for Women Living with HIV/AIDS and their Children in Resource-Constrained Settings. 2006 [http://www.who.int/hiv/pub/ mtct/guidelines/en/]. Accessed date 02 March 2010

9. Hitti J, Frenkel LM, Stek AM, Nachman SA, Baker D, Gonzalez-Garcia A, Provisor A, Thorpe EM, Paul ME, Foca M, Gandia J, Huang S, Wei LJ, Stevens LM, Watts DH, McNamara J: PACTG 1022 Study Team. Maternal toxicity with continuous nevirapine in pregnancy: results from PACTG 1022. Acquir Immune Defic Syndr 2004, 36(3):772-6.

10. Lyons F, Hopkins S, Kelleher B, McGeary A, Sheehan G, Geoghegan J, Bergin C, Mulcahy FM, McCormick PA: Maternal hepatotoxicity with nevirapine as part of combination antiretroviral therapy in pregnancy. HIV Med 2006, 7(4):255-60

11. Timmermans S, Tempelman C, Godfried MH, Nellen J, Dieleman J, Sprenger H, Schneider ME, de Wolf F, Boer K, van der Ende ME, Dutch HMF Study Group: Nelfinavir and nevirapine side effects during pregnancy. Aids 2005, 19(8):795-9.

12. Jamisse L, Balkus J, Hitti J, Gloyd S, Manuel R, Osman N, Djedje M, Farquhar C: Antiretroviral-associated toxicity among HIV-1-seropositive pregnant women in Mozambique receiving nevirapine-based regimens. J Acquir Immune Defic Syndr 2007, 44(4):371-6.

13. João EC, Calvet GA, Menezes JA, D'Ippolito MM, Cruz ML, Salgado LA, Matos HJ: Nevirapine toxicity in a cohort of HIV-1-infected pregnant women. Am J Obstet Gynecol 2006, 194(1):199-202.

14. Marazzi MC, Germano P, Liotta G, Guidotti G, Loureiro S, da Cruz Gomes A, Valls Blazquez MC, Narciso P, Perno CF, Mancinelli S, Palombi L: Safety of nevirapine-containing antiretroviral triple therapy regimens to prevent vertical transmission in an African cohort of HIV-1-infected pregnant women. HIV Med 2006, 7(5):338-44.

15. Phanuphak N, Apornpong T, Teeratakulpisarn S,

Chaithongwongwatthana S, Taweepolcharoen C, Mangclaviraj S, Limpongsanurak S, Jadwattanakul T, Eiamapichart P, Luesomboon W, Apisarnthanarak A, Kamudhamas A, Tangsathapornpong A, Vitavasiri C, Singhakowinta N, Attakornwattana V, Kriengsinyot R, Methajittiphun P, Chunloy K, Preetiyathorn W, Aumchantr T, Toro P, Abrams EJ, El-Sadr W, Phanuphak P: Nevirapine-associated toxicity in HIV-infected Thai men and women, including pregnant women. HIV Med 2007, 8(6):357-66.

16. Thomas T, Amornkul P, Mwidau J, Masaba R, Slutsker L, Mwaengo D, et al: Preliminary Findings: Incidence of Serious Adverse Events Attributed to Nevirapine among Women Enrolled in an Ongoing Trial Using HAART to Prevent Mother-to-Child HIV Transmission[Abstract 809]. In 12th Conference on Retroviruses and Opportunistic Infections Hynes Convention Center, Boston, Massachusetts; 2005

17. Myer L, Rabkin M, Abrams EJ, Rosenfield A, El-Sadr WM: Focus on women: linking HIV care and treatment with reproductive health services in the MTCT-Plus Initiative. Reprod Health Matters 2005, 13(25):136-46.

18. Tonwe-Gold B, Ekouevi DK, Bosse CA, Toure S, Koné M, Becquet R, Leroy V, Toro P, Dabis F, El Sadr WM, Abrams EJ: Implementing family-focused HIV care and treatment: the first 2 years' experience of the mother-tochild transmission-plus program in Abidjan, Cote d'Ivoire. Trop Med Int Health 2009, 14(2):204-12.

19. ANRS: (Agence Nationale de la Recherche sur le Sida). Echelle ANRS de cotation de gravité des événements indésirables cliniques graves chez l'adulte. 2010 [http://www.anrs.fr/Rubriques-transversales/Outils-pourla-recherche].

20. Kirkwood BR, Sterne JAC: Essential of Medical statistics. Second edition. Oxford, Blackwell Science Ltd; 2003.

21. Moh R, Danel C, Sorho S, Sauvageot D, Anzian A, Minga A, Gomis OB, Konga C, Inwoley A, Gabillard D, Bissagnene E, Salamon R, Anglaret X: Haematological changes in adults receiving a zidovudine-containing
HAART regimen in combination with cotrimoxazole in Cote d'Ivoire. Antivir Ther 2005, 10(5):615-24.

22. Isaakidis P, Raguenaud ME, Phe T, Khim SA, Kuoch S, Khem S, Reid T, Arnould $L$ : Evaluation of a systematic substitution of zidovudine for stavudine-based HAART in a program setting in rural Cambodia. $J$ Acquir Immune Defic Syndr 2008, 49(1):48-54.

23. Ssali F, Stöhr W, Munderi P, Reid A, Walker AS, Gibb DM, Mugyenyi P, Kityo C, Grosskurth H, Hakim J, Byakwaga H, Katabira E, Darbyshire JH, Gilks CF: DART Trial Team. Prevalence, incidence and predictors of severe anaemia with zidovudine-containing regimens in African adults with HIV infection within the DART trial. Antivir Ther 2006, 11(6):741-9.

24. Forna F, Liechty CA, Solberg P, Asiimwe F, Were W, Mermin J, Behumbiize $\mathrm{P}$, Tong T, Brooks JT, Weidle PJ: Clinical toxicity of highly active antiretroviral therapy in a home-based AIDS care program in rural Uganda. J Acquir Immune Defic Syndr 2007, 44(4):456-62.

25. Bersoff-Matcha SJ, Miller WC, Aberg JA, van Der Horst C, Hamrick HJ Jr, Powderly WG, Mundy LM: Sex differences in nevirapine rash. Clin Infect Dis 2001, 32(1):124-9.

26. Dieterich DT, Robinson PA, Love J, Stern JO: Drug-induced liver injury associated with the use of nonnucleoside reverse-transcriptase inhibitors. Clin Infect Dis 2004, 38(Suppl 2):S80-9.

27. Sulkowski MS, Thomas DL, Mehta SH, Chaisson RE, Moore RD: Hepatotoxicity associated with nevirapine or efavirenz-containing antiretroviral therapy: role of hepatitis $\mathrm{C}$ and $\mathrm{B}$ infections. Hepatology 2002, 35(1):182-9.

28. Chen ML: Ethnic or racial differences revisited: impact of dosage regimen and dosage form on pharmacokinetics and pharmacodynamics. Clin Pharmacokinet 2006, 45(10):957-64

29. Braitstein P, Brinkhof MW, Dabis F, Schechter M, Boulle A, Miotti P, Wood R, Laurent C, Sprinz E, Seyler C, Bangsberg DR, Balestre E, Sterne JA, May M, Egger M: Antiretroviral Therapy in Lower Income Countries (ART-LINC) Collaboration; ART Cohort Collaboration (ART-CC) groups. Mortality of HIV-1-infected patients in the first year of antiretroviral therapy: comparison between low-income and high-income countries. Lancet 2006, 367(9513):817-24

30. Etard JF, Ndiaye I, Thierry-Mieg M, Guèye NF, Guèye PM, Lanièce I, Dieng AB, Diouf A, Laurent C, Mboup S, Sow PS, Delaporte E: Mortality and causes of death in adults receiving highly active antiretroviral therapy in Senegal: a 7-year cohort study. AIDS 2006, 20(8):1181-9.

31. Ekouevi DK, Inwoley A, Tonwe-Gold B, Danel C, Becquet R, Viho I, Rouet F, Dabis F, Anglaret $X$, Leroy V: Variation of CD4 count and percentage during pregnancy and after delivery: implications for HAART initiation in resource-limited settings. AIDS Res Hum Retroviruses 2007, 23(12):1469-74

\section{Pre-publication history}

The pre-publication history for this paper can be accessed here: http://www.biomedcentral.com/1471-2334/10/188/prepub

doi: $10.1186 / 1471-2334-10-188$

Cite this article as: Coffie et al., Incidence and risk factors of severe adverse events with nevirapine-based antiretroviral therapy in HIV-infected women MTCT-Plus program, Abidjan, Côte d'Ivoire BMC Infectious Diseases 2010, 10:188

\section{Submit your next manuscript to BioMed Central} and take full advantage of:

- Convenient online submission

- Thorough peer review

- No space constraints or color figure charges

- Immediate publication on acceptance

- Inclusion in PubMed, CAS, Scopus and Google Scholar

- Research which is freely available for redistribution 